\title{
CONSTITUCIONALISMO E BATALHAS POLÍTICAS NA ARGENTINA: ELEMENTOS PARA UMA HISTÓRIA SOCIAL
}

Constituitonalism and political battles in Argentina: elements for a social history

\author{
FABIANO ENGELMANN E LUCIANA RODRIGUes PENNA
}

http://dx.doi.org/10.1590/S2178-14942016000200010

Fabiano Engelmann é professor da Pós-Graduação em Ciência Política da UFRGS (fabengel@gmail.com).

Luciana Rodrigues Penna é doutora em Ciência Política pela UFRGS (luciarp@via-rs.net).

Artigo recebido em 3 de abril e aprovado para publicação em 15 de junho de 2016. 


\title{
Resumo
}

0 artigo propõe elementos para uma história social do constitucionalismo e sua relação com as batalhas políticas na Argentina. 0 investimento das diferentes frações da elite política na interpretação constitucional é analisado como uma das estratégias de legitimação de sucessivos regimes políticos visando à sua formalização na técnica jurídica. A primeira parte trata dos contornos sócio-históricos do constitucionalismo argentino, com ênfase na sua legitimação no âmbito acadêmico. A segunda se debruça sobre a intensificação dos usos políticos do Direito Constitucional e as modalidades de intersecção de seus agentes no espaço político.

Palavras-CHAVE: constitucionalismo, Argentina, batalhas políticas.

\begin{abstract}
The article proposes elements for a social history of constitutionalism and its relation to the political battles in Argentina. The investment of the different fractions of the political elite in the constitutional interpretation is considered as one of the legitimation strategies of successive political regimes aiming at its formalisation in the juridical technique. The first part deals with the socio-historical contours of Argentine constitutionalism with emphasis on its legitimacy in the academic field. The second part focuses on the intensification of the political uses of Constitutional Law and the modalities of intersection of its agents in the political space.
\end{abstract}

KeYwords: constitutionalism, Argentina, political battles.

\section{Resumé}

L'article propose des éléments pour l'histoire sociale du constitutionnalisme et de ses rapports avec les batailles politiques en Argentine. L'investissement des différentes fractions de l'élite politique dans l'interprétation constitutionnelle est considérée comme l'une des stratégies de légitimation des régimes politiques successifs visant sa formalisation juridique. La première partie traite des contours socio-historiques du constitutionnalisme Argentin en mettant l'accent sur sa légitimité dans le domaine académique. La deuxième partie se concentre sur l'intensification des usages politiques du droit constitutionnel et les modalités d'intersection de ses agents dans l'espace politique.

Mots-CLẾS: constitutionnalisme, Argentine, batailles politiques. 


\section{Doutrinas Jurídicas E batalhas POLÍTICAS: PARA UMA HISTÓRIA SOCIAL}

$\mathrm{E}$ ste texto resulta de uma pesquisa mais abrangente sobre a construção da legitimidade 1 política das instituições judiciais na América Latina. Embora os modelos jurídico-políticos dos países latino-americanos tenham origem comum na tradição da civil-law européia, ${ }^{2}$ diferentes aspectos relacionados à trajetória histórica de cada país intervêm no condicionamento das relações entre a esfera política e a esfera judicial. ${ }^{3}$ Entre estes, podem ser citadas as modalidades de inserção dos bacharéis em Direito na política e mais amplamente, já que a interação entre as elites judiciais e as elites políticas são muito importantes para a trajetória de cada país. Nesse sentido, a apreensão do espaço de intersecção entre juristas e políticos relaciona-se diretamente com a produção das doutrinas jurídicas, saberes que operam como uma verdadeira linguagem de Estado servindo para conferir legitimidade a diferentes formas de poder que variam conjunturalmente. Partindo dessa problemática mais ampla, nos propomos analisar a relação entre a intervenção dos constitucionalistas e a legitimação de diferentes modelos políticos ao longo da história da Argentina. A leitura desse caso nos parece bastante interessante para o aprofundamento dos referenciais de estudo das complexas inter-relações que circundam os juristas e o poder político em dinâmicas importadoras de modelos institucionais com trajetória recente na construção de regimes constitucionais. ${ }^{4}$

Abordar a produção intelectual dos profissionais do Direito do ponto de vista das ciências sociais tem como pressuposto evitar a representação ideológica que os juristas constroem a seu respeito, em especial a ideia de que o debate doutrinário é um debate "técnico", objeto de especialistas e autônomo em relação às polarizações políticas. As doutrinas jurídicas - saber erudito que está na base dos argumentos de autoridade dos juristas - são difundidas através da edição de obras, individuais ou coletivas, assinadas por especialistas dotados legitimidade acadêmica, que contribuem para a formação dos sentidos compartilhados entre os juristas sobre o processo político e a execução das políticas públicas. Uma das dimensões mais visíveis do fenômeno é a presença em diferentes cenários políticos dos "constitucionalistas", categoria de agentes encarregada de difundir a interpretação do sentido da regra constitucional mobilizada tanto em tomadas de decisão judicial em cortes constitucionais, quanto nos atos decisórios de governos. 
Enfocar a emergência dessa categoria e sua presença na construção da legitimidade de regimes políticos não implica desconsiderar todo o conjunto de agentes que participa do debate político em torno de princípios constitucionais, incluindo uma larga "comunidade de intérpretes" tais como jornalistas, cientistas sociais e mesmo diferentes lideranças políticas. A questão essencial que pretendemos propor neste trabalho é que, em um sentido, o debate constitucional é fortemente agendado por aqueles que detêm o monopólio de dizer o Direito. E, em outro sentido, os agentes - no curso de batalhas políticas - apropriam-se do debate constitucional como forma de conferir legitimidade a arranjos institucionais que lhes garantem o poder político.

Tem-se assim a transformação do debate sobre questões políticas em um debate entre especialistas, sobre a forma à qual se devem adequar os atores quando abordam questões públicas. No entanto, a crescente imposição, como evidente, do saber disciplinar e doutrinário do Direito Constitucional encarnando o "sentido correto" da atividade política dificulta a compreensão do papel exercido por essa espécie de saber-erudito no jogo político. Para uma melhor análise da legitimação das doutrinas constitucionais e dos seus especialistas no espaço público, Lacroix (1992) propõe o estudo dos autores da formalização jurídica, sua relação com o espaço político e não apenas a análise das idéias do Direito Constitucional em abstrato.

A relação entre os limites e possibilidades de uso do conhecimento jurídico e da intervenção dos juristas na construção da legitimidade de regimes políticos na América Latina é abordada em diferentes trabalhos, entre os quais se pode mencionar Dezalay \& Garth (2001), Almeida (2014), Engelmann (2006) e Vecchiolli \& Santa Maria (2008). Na perspectiva adotada por esses trabalhos, a discussão constitucional animada pelos juristas dissimula o arbitrário presente nas "escolhas interpretativas" que se confrontam nas lutas políticas pela definição do papel do Estado. Ou seja, seguindo Bourdieu (1986), podemos afirmar que a força simbólica do Direito é a arma que confere aos juristas um poder performativo sobre o sentido das instituições posicionando-os em um espaço central nas disputas pelo sentido do poder de Estado.

A força simbólica representada pelo Direito e pelas categorias de juristas que detêm o monopólio de dizer o sentido correto das normas é crescentemente mobilizada pelos atores políticos como recurso de legitimação de seu poder. A crescente "juridicização" do mundo político é evidenciada nos trabalhos que propõem uma história social dos debates jurídicos na Europa (Charle, 1997 e 1989; Chevalier, 1993, e Commaille, 2010). Charle (1997) chama a atenção para a afirmação de diferentes categorias de profissionais do Direito na França do século XIX como fração importante da elite burocrática que transpassa o Ancien Régime. ${ }^{5}$ Dezalay (1993) aborda a importância de uma história social das batalhas doutrinais. 0 autor aprofunda a discussão sobre a mudança de status da doutrina jurídica frente ao surgimento 
de um mercado internacionalizado que põe em jogo diretamente o sentido político das instituições e, em última instância, as orientações do poder de Estado.

Mais especificamente sobre a importância das doutrinas constitucionais e seus especialistas, Lacroix (1992), François (1993; 1996) e Sacriste (2011), Poirmeur \& Bernard (1993), Poirmeur \& Rosemberg (1989) fornecem referências importantes. A partir do caso francês, demonstram que nos anos 1960 há um fortalecimento do debate constitucional resultante da afirmação do caráter jurisdicional da atuação Conselho Constitucional e do intenso trabalho de construção doutrinária entre os juristas (Poirmeur \& Rosemberg, 1989: 233). 0 trabalho de Sacriste (2011) aborda o cenário francês de fins do século XIX apontando como emergiu a figura do constitucionalista dentro do regime republicano e o papel político assumido pelos professores de Direito Constitucional das Faculdades de Direito na legitimação da causa republicana.

Lacroix (1992) analisa o cenário dos anos 90 observando que os constitucionalistas franceses romperam com a clausura universitária se inserindo na esfera midiática, onde disputam a atenção da opinião pública com outros profissionais, como jornalistas, economistas e cientistas políticos. No Brasil, contamos com análises sócio-históricas sobre os usos políticos da interpretação constitucional durante o Império (Penna, 2014) e sobre o "retorno" e fortalecimento do espaço dos constitucionalistas após a promulgação da Constituição de 1988 (Engelmann e Penna, 2014).

Tomando como ponto de partida a tentativa de construção de história social ${ }^{6}$ do constitucionalismo argentino, compusemos o banco de dados da pesquisa rastreando as intervenções dos constitucionalistas argentinos para apreender as principais condicionantes da relação desses juristas com o universo político. Para isso, foram privilegiadas fontes primárias e secundárias. Para apreendermos a construção histórica do constitucionalismo e sua ascensão como discurso de Estado na Argentina, recorremos à análise de textos sobre a "evolução do discurso constitucional na Argentina" (Dalla Via, 2007) e sobre a história do ensino da cátedra de Direito Constitucional na Faculdade de Direito da Universidade de Buenos Aires. ${ }^{7}$ Em seguida, para abordarmos o cenário da última década, utilizamos como fontes 1) os manuais jurídicos mais citados no ensino de Direito Constitucional, como caminho para identificar não apenas os agentes desse espaço, mas seus percursos e suas tomadas de posição nas batalhas políticas; 2) as intervenções desses juristas na imprensa nacional. A utilização de manuais de Direito como fontes para a compreensão das controvérsias jurídicas travadas em determinado regime político advém de uma abordagem metodológica desenvolvida recentemente nas ciências sociais brasileiras no estudo do espaço jurídico.

Nesta perspectiva, o poder político se expressa como saber e linguagem jurídica, e por isso a produção "doutrinária" é fenômeno recorrente, contínuo, e as obras jurídicas são reproduzidas em larga escala. 0 catecismo jurídico-político é veiculado sobretudo pela via dos 
manuais de Direito, modalidade do discurso político posta na forma da técnica jurídica. Assim, tem-se uma dimensão de poder político que passa despercebido, acumulando sua maior eficácia simbólica exatamente na medida em que é tomado como neutro, técnico e científico. 0 discurso da "doutrina jurídica"8 é a ferramenta que interpreta, reinterpreta e conduz à legitimação de todas as produções finais que emergem do campo do Direito: decisões administrativas, sentenças judiciais, decretos e leis. É no universo dos manuais jurídicos que tais produtos encontram força simbólica, sua base de sustentação. Portanto, é preciso tratar a emergência dos manuais de forma coletiva e não vaga, esclarecendo o contexto em que esses discursos são construídos. ${ }^{9}$

A categoria de constitucionalista é assim uma definição central para a presente discussão, tomada aqui como a posição social que legitima um agente ou conjunto de agentes a definir os contornos jurídicos da vida social e política, mobilizando para isso a noção de "Constituição". "Interpretar a Constituição" é, neste sentido, um ato político. Ele se inscreve nas lutas políticas de um período determinado e usa a figura da "Constituição" como referência normativa na mobilização doutrinária de múltiplos saberes, em que define o mundo, ora pela legitimação, ora pela contestação da ordem política. Portanto, buscamos identificar quais os manuais mais citados através da bibliografia geral de Direito Constitucional indicada nos Programas de Ensino das duas Faculdades de Direito centrais do país: a Universidade de Buenos Aires e a Pontifícia Universidade Católica Argentina. Assim, compusemos uma primeira amostra de agentes para, em seguida, pesquisar seus trajetos de produção teórica, atuação política e intervenções na mídia.

Quanto ao poder de difusão ideológica dos manuais jurídicos dentro do espaço universitário, é relevante apontar que a Argentina conta, no último decênio, com 111 universidades, entre instituições públicas e privadas, ${ }^{10}$ em que funcionam 55 Faculdades de Direito ${ }^{11}$ localizadas em diferentes regiões do país. Em função da dificuldade de obter dados mais aprofundados sobre um universo tão amplo, optamos por centrar a exploração nas Faculdades de Direito mais centrais do país, mesmo reconhecendo a existência de cursos tradicionais situados em universidades de outras províncias, tais como Córdoba, Rosário, La Plata e Tucumán.

Quanto ao recorte temporal, optamos por manter uma perspectiva geral, e assim não confinamos a pesquisa a um marco cronológico exclusivo, embora a análise das tomadas de posição dos constitucionalistas circunscrita ao período contemporâneo tenha sido desenvolvida a partir da Reforma de 1994.

\section{Doutrinas CONSTITUCIONAIS NA ARGENTINA: ENTRE A CÁTEDRA E AS BATALHAS POLÍTICAS}

nalisar os usos políticos das doutrinas constitucionais não consiste apenas em ma-
pear o espaço de seus agentes, apontar os conceitos-chave empregados ou elencar 
as vertentes ou "escolas" do constitucionalismo, embora esses dados sejam relevantes para a delimitação do objeto de estudo. É necessário problematizar a estruturação desse poder de nomeação, ancorado na representação social do constitucionalista como o especialista da definição legítima do Estado e das políticas públicas. Vale frisar que o termo não possui sentido unívoco nem mesmo na discussão jurídica, pois congrega um conjunto diversificado e mesmo contraditório de referenciais teóricos e matrizes ideológicas. É possível encontrar expressões como Constitucionalismo Liberal, Constitucionalismo Social, Constitucionalismo Contemporâneo. Verifica-se ainda a remissão a sentidos vinculados a experiências políticas históricas, nacionais ou regionais, como: Constitucionalismo Mexicano, Constitucionalismo Francês, Constitucionalismo Latino-Americano (Avritzer, 2013).

Neste sentido, o constitucionalismo argentino, tal como o brasileiro, e os casos de outros países latino-americanos apresentam aspectos comuns. Os países da América Latina compõem um cenário em que há sucessivas "interrupções" ou "suspensões" da vigência constitucional, ou seja, há vários momentos constituintes. Isto torna mais complexa a análise dos ascensos e descensos do constitucionalismo no espaço político. Algumas abordagens institucionalistas da Ciência Política entendem essas reiteradas "suspensões da ordem constitucional" ou diversas "convenções constituintes" do cenário argentino (e latino-americano) sob a ótica da path dependency, lendo-as como uma permanente instrumentalização da Constituição em face da reprodução de uma dinâmica de um "hiperpresidencialismo". Entendidas como sinal da ausência de um "pacto constituinte estável" elas tornariam as democracias latino-americanas instáveis e suscetíveis às rupturas ditatoriais, quadro em que a Argentina representaria um caso bastante típico (Freer, 2012; Negretto, 2016).

De modo diverso, analisamos a recorrência das conjunturas constituintes ou de sucessivas reformas constitucionais não como indicativos da renitente ocorrência de golpes e rupturas que têm obstaculizado a estabilidade democrática, mas como um reflexo do apego das elites políticas à figura da Constituição. Pode-se entender esse fenômeno como uma estratégia de legitimação que beneficia as elites políticas no poder em um cenário de internacionalização do Rule of Law iniciado após a Segunda Guerra Mundial.

Essa estratégia se dá através do investimento dos juristas na autonomização relativa do discurso jurídico na forma de constitucionalismo, o que ocorreu tanto na Argentina quanto em outros casos da América Latina (ver Penna \& Engelmann, 2014 e Perdomo, 2011). Tal processo indica: 1) a percepção das elites sobre a politicidade do Direito (a interpretação da regra como ferramenta de sustentação de iniciativas políticas e a possibilidade de formatação jurídico-constitucional das decisões); 2) que não se trata de um fenômeno recente, mas de um investimento de longa duração imerso na concorrência pelos sentidos do "Estado de Direito" por parte das 
elites locais importadoras de saberes dos países centrais. ${ }^{12}$ Logo, não podemos considerar 0 marco representado pela Reforma Constitucional de 1994, nem outros "marcos constitucionais" anteriores - quando tomados isoladamente - como elementos explicativos suficientes da relação entre constitucionalismo e política no cenário argentino. Ao contrário, é importante alcançar uma perspectiva de longa duração e adentrar no contexto dos passos iniciais situados no século XIX (Bouzas, 2006; Luna, 1996; Zimmerman, 2010). Naquele período, dentro da elite política já se diferenciava a figura do publicista apto à elaboração das noções que poderiam formalizar o Estado nacional. Neste sentido, podemos verificar que os constitucionalistas argentinos desde 0 século XIX estiveram imbricados com estratégias de ação política (Dalla Via, 2007).

Nesses termos, a trajetória do constitucionalismo na Argentina reflete intensa politicidade em um processo de longa duração que imbricou política e Direito desde o século XIX, quando as elites mobilizaram a doutrina constituciona/ para a tarefa de construção do Estado na figura do jurista liberal conservador Juan Bautista Alberdi. Ele foi o publicista que naquele momento atendeu à demanda das frações dominantes e apresentou um receituário de teor liberal para o texto da primeira Constituição Argentina em 1853. ${ }^{13}$ Dentro do pensamento hegemônico da época, o liberalismo jurídico de tom conservador de Juan Alberdi repercutia noções adotadas pelos congressistas argentinos de 1853, uma tendência doutrinária que permaneceu dominante até a aprovação da Lei Saenz Peña em 1912 ampliando a participação democrática e o direito ao sufrágio.

Assim, na "Escola Doutrinária Alberdiana" encontramos uma defesa da liberdade contratual e econômica, com posição de forte incentivo à imigração anglo-saxônica, e pouca consideração pela defesa das liberdades de participação política. A doutrina constitucional liberal de Alberdi justificava o "governo dos mais aptos e melhores, enquanto a sociedade argentina ainda não ostentasse as condições para exercer a cidadania" (Luna, 1996: 68). Naquele período de convulsões em torno da unificação nacional ${ }^{14}$ e de fundação das primeiras escolas jurídicas, a concepção predominante sobre o sentido legítimo do Direito estava dominada pela ancestralidade e pelo uso forense do Direito Civil, visto como o Direito "prático" ou o Direito "dos advogados". Desta forma, o Direito Constitucional ainda tinha poucos adeptos entre os docentes e ocupava uma posição periférica na hierarquia do ensino jurídico acoplado ao Direito Administrativo e à Filosofia Política quando se tratava de teorizar sobre o Estado (Tanzi, 2011).

Esse olhar histórico sobre o ensino de Direito Constitucional na Faculdade de Direito de Buenos Aires nos indica o longo caminho percorrido por seus adeptos, existindo previsão da disciplina na Universidade de Córdoba desde 1834. Deste momento até a cátedra ser oferecida na Universidade de Buenos Aires em 1855 e efetivamente ministrada na mesma instituição em 1868, decorreram mais de duas décadas. Tal fato pode ser tomado como 
indicativo da baixa atratividade desse saber para a esfera política diante de outras disciplinas mais amplamente vinculadas à administração pública, como o Direito Financeiro ou o Direito Administrativo ${ }^{15}$ (Tanzi, 2011:86). Isto explica por que o Direito Constitucional só se separou formalmente do Direito Administrativo em 1873, mas ainda permanecendo ambos sob a responsabilidade do mesmo professor (Tanzi, 2011: 89). Em 1922, a disciplina passou a denominar-se "Direito Constitucional Argentino e Comparado" e somente em 1952 foi criada a cátedra de História Constitucional (Idem).

Todavia, apesar da restrita autonomia do Direito Constitucional enquanto disciplina acadêmica, o quadro de disputas intra-elites pela definição do papel do Estado entre fins do século XIX e começo do século XX fomentava os debates de teor publicista. Os catedráticos das escolas de Direito da região platina, abarcando juristas liberal-reformistas de Buenos Aires, Córdoba, La Plata e Montevidéu, investiram em tomadas de posição "críticas" ao regime. ${ }^{16} 0$ enfrentamento ocorria contra as posições liberais conservadoras predominantes nas cátedras universitárias, articulado por juristas com posições reformistas discutindo o papel do Estado em face de direitos sociais, políticos, da igualdade de oportunidades e da justiça distributiva. Para isso, eles mobilizaram a Sociologia e a Filosofia, bases do denominado "Direito Político", indicando um processo de relativo distanciamento da expertise publicista dos juristas em relação aos políticos (Bouzas, 2006: 125).

Portanto, no final do século XIX e começo do século XX, mesmo com o Direito Político ou Constitucional ministrado ainda com predominância oratória nas Faculdades e pouco valorizado pelos discentes, que o consideravam "matéria fácil, sujeita à inventiva e à improvisação" (Tanzi, 2011: 100), com reduzida produção teórica (marcada pelo prestígio do modelo anglo-saxão entre os juristas argentinos), já se identificam esforços pontuais para a incorporação de análises da "Constituição Argentina". Naquele momento, obras jurídicas em formato de manuais introduziam temas jurídicos nacionais contemplando comentários aos dispositivos da Constituição de 1853 e análises da jurisprudência da Suprema Corte da Nação.

Porém foi o "ciclo peronista" que introduziu um conjunto de demandas sociais na tarefa da Convenção Constituinte repercutindo essa tendência no plano da doutrina jurídica, já representada como "Constitucionalismo Social" (Loenzo, 2010: 164). Com o primeiro governo de Juan Perón (1946-1955), o nacionalismo passa a permear os programas da cátedra, tanto pela temática do "desenvolvimento dos problemas políticos nacionais", quanto pela obrigatoriedade do ensino da Constituição Argentina reformada e sancionada em 1949.

Essa preocupação ideológica pode ser tomada como indicativa do esforço da elite política do regime peronista em intervir no ensino jurídico e na busca de sua legitimação pelo viés da doutrina constitucional (Loenzo, 2000). A cátedra de Direito Constitucional reflete a 
mudança política nacional, com a demissão de docentes e a nomeação de novos, já ligados ao peronismo, como o deputado Juan Isaac Cooke e, posteriormente, o jurista católico Marcelo Roberto Sanchez Sorondo (Tanzi, 2011: 104). Esse aspecto remete à crescente politização do constitucionalismo e à apropriação política de seu discurso.

A queda do Regime Peronista e o início do Regime Militar autodenominado Plano de Reconstrução Nacional - PRN (1955-1973) inauguraram um ciclo de governos com viés autoritário, o que repercutiu diretamente no ensino de Direito Constitucional, especialmente na Universidade de Buenos Aires. Retornaram aos postos os professores que haviam sido dispensados no período peronista, e a cátedra de História Constitucional, antes a cargo do peronista Marcelo Sorondo, passou a ser ministrada por Héctor Lanfranco e Segundo Linares Quintana.

O primeiro governo Perón promoveu uma politização dos usos do Direito Constitucional com uma apropriação "social", "nacionalista" e "desenvolvimentista". Um uso político diverso foi conferido à doutrina a partir do contexto do Regime Militar de 1955-73, que buscou uma apropriação da Constituição de 1853 e das Reformas de 1860 e 1866, ou seja, da ideologia alberdiana. Os constitucionalistas alinhados ao Regime ascenderam aos postos docentes principais, como foam os casos representativos de Héctor Lanfranco, Linares Quintana e Alberto Padilla, todos professores de Direito Constitucional na Universidade de Buenos Aires (Tanzi, 2011: 105). Alinhados ao Regime Militar de 1955-1973, Héctor Lanfranco, Alberto Padilla Gallo e Segundo Victor Linares Quintana possuem percursos que apontam a combinação de atuação em altos postos políticos e posições no universo empresarial, com investimento docente e publicações doutrinárias. Entre esses autores fica nítido o alinhamento ideológico com o Liberal-Conservadorismo dos intelectuais anti-Peronistas aglutinados no denominado Grupo Azcuénaga17 (Morresi, 2010; Vicente, 2012).

Nas produções que mobilizaram, a ideia da unidade da História Constitucional Argentina, como referido, aparece na apropriação do sentido da Constituição de 1853 e da Reforma de 1860, como um elemento chave para a defesa a legitimidade jurídica do governo militar. A noção de tradição liberal, conservadora e católica remete ao "espírito ocidental" ao qual a Argentina estaria ligada. Dotando o autoritarismo de um sentido de continuidade histórica, os constitucionalistas que apoiaram o regime militar apregoaram que a tradição constitucional argentina, fundada na "ordem e na liberdade" teria sido afrontada com a democratização de 1912 e interrompida desde os anos 40, com o advento do Peronismo (Moressi, 2010; Vicente, 2012).

Uma exploração preliminar de seus trajetos políticos, acadêmicos e profissionais contribui para a apreensão da imbricação desses juristas com o espaço do poder político evidenciando sua múltipla inserção e a porosidade das esferas acadêmica e do poder político. 


\section{Amostra de constitucionalistas do regime de 1955-1973 (Plano de Reconstrução Nacional)}

\begin{tabular}{|c|c|}
\hline Nome & $\begin{array}{l}\text { Publicações/ } \\
\text { Conferências }\end{array}$ \\
\hline $\begin{array}{l}\text { Héctor } \\
\text { Lanfranco }\end{array}$ & $\begin{array}{l}1981 \text { - Nomeado Membro da } \\
\text { Academia Nacional de Ciencias } \\
\text { Morales y Políticas } \\
\text { Em19 de outubro deste ano } \\
\text { pronunciou a conferência "Una } \\
\text { trascendenteamistad: Echeverría, } \\
\text { Alberdi y Gutiérrez" }\end{array}$ \\
\hline $\begin{array}{l}\text { Alberto } \\
\text { Gabriel } \\
\text { Padilla Gallo }\end{array}$ & $\begin{array}{l}\text { "La Constitución de los Estados } \\
\text { Unidos como precedente } \\
\text { argentino"; Jurisprudencia } \\
\text { Constitucional de la Corte } \\
\text { Americana"; } \\
\text { "El Presidente de los EEUU, } \\
\text { sufunción y sus poderes"; } \\
\text { "La Invocación del Preámbulo"; } \\
\text { "Historia Externa de la } \\
\text { Constitución"; } \\
\text { "Lecciones sobre la } \\
\text { Constitución" (dos ediciones); } \\
\text { "El significado delAcuerdo de } \\
\text { San Nicolás"; } \\
\text { "La idea federal entre nosotros"; } \\
\text { "La Reforma de 1957" }\end{array}$ \\
\hline
\end{tabular}

Segundo

Diretor del "Boletín de la

Victor Linares Biblioteca del Congreso

Quintana Nacional", 1934/42.

Diretor Fundador de "Anales de

Legislación Argentina", editados por "La Ley", tomo I, 1940. Diretor da Revista "Labor", publicação especializada em Direito Laboral, editada pelo Departamento del Trabajo de la Provincia de Buenos Aires, 1942/43.

Diretor de "Anales de la Academia Nacional de Ciencias Morales y Políticas".

Codiretor de "Anales de la Academia Nacional de Derecho y Ciencias Sociales de Buenos Aires".

Diretor fundador da "Revista Argentina de Ciencia Política", 1960/1962.

\section{Postos políticos e} profissionais

Trajeto acadêmico

1957-1958 - Embaixador e Ministro Advogado. Universidade Nacional de La Plenipotenciário na República do Equador (Governo do General Aramburu).

1962 - Durante o Governo de José María Guido e na Intervenção de Ceferino P. Merbilháa: Ministro de Governo da Província de Buenos Aires.

Conjuez da Corte Suprema da Província de Buenos Aires por 25anos consecutivos; Conjuez da Corte Suprema de Justiça da Nação em: 1971, 1973, 1977.

Vinculado durante mais de meio século ao Banco de Boston, na qualidade de Advogado-labor; Advogado em outras empresas e atuante em diversas diretorias: Presidente de Silvana Argentina S. A. y de Monsanto Argentina S.A. Plata. 1933 - Subencarregado do Curso de Elementos de Derecho Público na cátedra de Notariado y Procuración - Faculdade de Direito de Bueno Aires;

1939 - Professor adjunto de Derecho e Historia Constitucional na Carreira de Advocacia;

1957 - Professor titular da Cátedra. Renuncia em 1946.

$\begin{array}{ll}\text { y de Monsanto Argentina S.A. } & \text { (1952/56). } \\ & \text { Membro da Academia de Derecho y } \\ & \text { Ciencias Sociales (sitial de Félix Frías) desde } \\ & 1956 \text { e seu Presidente } \\ & \text { entre } 1974 \text { e } 1977 . \\ & \text { Membro da Academia de Ciências Morales y } \\ & \text { Políticas. } \\ & \text { Doutor Honoris Causa da Universidade } \\ & \text { Nacional de Tucumán. }\end{array}$

Ex-Assessor Legislativo da Biblioteca do Congresso da Nação:1931/1942. Diretor Geral do Departamento de Trabalho da Província de Buenos Aires, 1942.

Diretor Geral de Estabelecimentos Penais da Província de Buenos Aires, 1943.

Diretor Geral de Assuntos Jurídicos do Ministério do Interior (1955/1956 e 1963/1966).

Membro Honorário do Colégio de Advogados de Buenos Aires. Membro do Escritório "Linares Quintana, Badeni\&Gagliardo" Capital Federal

\section{Advogado.}

Doutor em Direito e Ciências Sociais pela Universidade de Buenos Aires;

Professor d eDireito Constitucional na mesma Faculdade, onde foi Interventor em 1955.

Presidente do Colégio de Advogados (1952/56).

Ciencias Sociales (sitial de Félix Frías) desde 1956 e seu Presidente

Doutor Honoris Causa da Universidade

1933 - Graduação em Direito na Faculdade de Direito da Universidade de Buenos Aires. Professor Titular Emérito de Derecho Constitucional de la Universidade de Buenos Aires.

Professor Titular Emérito de Derecho Constitucional da Universidade de La Plata. Ex-Professor Ordinário Titular de Derecho Constitucional na Faculdade de Derecho y Ciencias Sociales de Buenos Aires (carreira docente, iniciada em 1934, desde Adscrito, Professor Adjunto e finalmente Professor Ordinário Titular por concurso de oposição, títulos e antecedentes durante quarenta anos).

Ex-Professor Ordinário Titular de Derecho Constitucional da Faculdade de Ciencias Jurídicas y Sociales de La Plata (como culminação de una prolongada carreira docente iniciada em 1940, desde Professor Adscrito, Professor Adjunto e Professor Ordinário Titular, por concurso de oposição, títulos e antecedentes durante quarenta anos

Fonte: Banco de dados do Projeto: "Legitimidade Política do Poder Judi cial na América Latina: configurações institucionais e sócio-políticas do Judiciário e suas elites na Argentina, Brasil, Chile, Colômbia e Venezuela na década de 2000". 
Pelos dados reunidos verificamos a combinação de inserção política e acadêmica dos agentes e, portanto, a mobilização do publicismo com teor anti-Peronista posto a serviço dos interesses militares, apoiado em perspectivas institucionais (Donghi, 2013). Observamos que a questão de fundo que perfaz os embates doutrinários desse período está ligada à oposição entre a denominada "doutrina de fato" e a "doutrina da via constitucional". A "doutrina de fato" , construída como legitimação do poder em face da não-vigência da Constituição nos Regimes Autoritário,s foi elaborada a partir da "Acordada" da Corte Suprema da Nação e editada durante o Golpe Militar de 1930. ${ }^{18}$ Ela situou o fundamento do sistema jurídico no "direito da revolução triunfante" , cujo Estatuto era predominantemente formalizado em decretos-lei e não na Constituição nacional (Lorenzo, 2010:119). Em face das sucessivas rupturas políticas que colocaram em suspenso a vigência da Constituição (1930, 1943, 1955, 1976), essa tese se manteve em permanente reelaboração, recebendo diferentes interpretações dos constitucionalistas alinhados aos governos militares (Dalla Via, 2007:4).

A batalha doutrinária contra esta linha ideológica surgiu como aposta de um grupo de juristas engajados na construção da autonomia relativa do constitucionalismo. 0 que demandou um trabalho constante de enfrentamento da "doutrina de fato" - cuja origem foi jurisprudencial - para reposicionar o fundamento da juridicidade na Constituição, o que restituía o monopólio dos constitucionalistas na interpretação das normas. Isso pode ser constatado na atuação de um grupo de juristas que assumem, na década de 70, a tarefa da construção de uma "saída" ou "transição" do Regime Militar para a via democrática, através do caminho das emendas constitucionais ${ }^{19}$. Durante a presidência do General Alejandro Augustín Lanusse (1971-1973), essa fração da elite dos constitucionalistas promoveu a "redemocratização constitucional do país", integrando a denominada "Comissão Assessora para a Reforma Institucional" que englobava uma proposta de mudança na legislação eleitoral argentina: Germán Bidart Campos, Carlos María Bidegain, Natalio Botana, Carlos S. Fayt, Pedro Frías, Julio Oyharte, Dardo Perez Guilhou, Adolfo Rozaut, Alberto Antonio Spota e Jorge Vanossi (Dalla Via, 2007; Lorenzo, 2000).

Desta forma, verificamos que, no caso argentino, a partir dos anos 50 houve uma tendência à intensificação da apropriação do constitucionalismo pela política e, a partir dos anos 70, um esforço de apropriação da política pelo constitucionalismo. Ou seja, uma combinação visível pela progressiva diversificação e autonomização do espaço dos novos especialistas em Constituição e pela estratégia das elites políticas de se apropriar do discurso constitucional. Outro dado que confirma essa tendência dúplice é a emergência de diferentes "escolas doutrinárias" indicando a maior especialização dos embates diante das problemáticas políticas nacionais e regionais (provinciais e municipais). 0 espaço de produção de doutrinas abriga 
constitucionalistas que se agrupam em torno de representações distintas: Escola Liberal, Escola Católica, Escola Platense, Escola Alberdiana, Escola Socialista e Escola Decisionista, englobando os nacionalistas (Aja Espil apud Dalla Via, 2007).

Outro efeito da apropriação contestadora do Regime Militar na década de 70 - a partir da significativa expansão da produção doutrinária no constitucionalismo - residiu na iniciativa fundadora de uma rede internacional de constitucionalistas: o Instituto Ibero-americano de Direito Constitucional. ${ }^{20}$ Em 1974, com a criação do instituto, reuniram-se vários juristas, como Antonio María Hernández, Pedro José Frías, Gérman Bidart Campos, Jorge Reinaldo Vanossi e Humberto Quiroga Lavié, compondo uma rede mobilizada para a internacionalização do discurso crítico ao predomínio dos governos militares. Os membros do instituto posicionaram o debate constitucional no âmbito dos temas políticos referentes aos países latino-americanos expandindo as relações entre os juristas e a discussão da política em um contexto ainda mergulhado em regimes ditatoriais.

Constatamos que juristas de várias universidades participaram, porém havia uma predominância de professores da Universidade de Buenos Aires. Germán Bidart Campos, jurista católico e docente da Universidade de Buenos Aires, é um caso representativo desse empenho na intensificação da produção teórica como estratégia combinada com a defesa do caminho de compromisso constitucional para uma transição para a democracia. Com dezenas de manuais publicados entre 1960 e 2004, escritos a partir do posto de Direção da Revista Jurídica El Derecho (Dalla Via, 2007: 15) ele difundiu uma orientação jusnaturalista e liberal-católica reivindicando a democracia pela defesa da Suprema Corte da Nação enquanto instância máxima de garantia dos direitos civis. Para Campos, o Judiciário era o pilar da supremacia da Constituição, e a vigência desta, por sua vez, era sinônimo de superação dos "governos de fato". No caso de German Bidart Campos, o volume da produção, a docência na Universidade de Buenos Aires e o posicionamento liberal contribuíram para a reedição de suas obras, além da prestação de consultoria jurídica especializada em assuntos político-administrativos ao longo de mais de cinco décadas. ${ }^{21}$

\section{O REGIME DEMOCRÁTICO E A DIVERSIFICAÇÃO DOS SENTIDOS DO CONSTITUCIONALISMO}

Tá a partir dos anos 1980, com o processo de redemocratização, houve uma tendência à promoção do constitucionalismo, manifestada pela proliferação de centros de pesquisa, institutos e associações de juristas vinculados à disciplina. A Associação Argentina de Direito Constitucional, fundada em 1979, apontou o prestígio dessa expertise, formando uma 
rede nacional, com posição central na área, que contava em 2015 com 808 associados. ${ }^{22}$ Entre outras redes que reuniram constitucionalistas argentinos, podemos destacar o Centro de Direito Constitucional da Pontifícia Universidade Católica Argentina (PUCA), dirigido por Orlando Gallo; o Centro de Investigaciones en Derecho Constitucional y Ciencia Politica Jose Benhjamin Gorostiaga da Universidade Nacional de Tucuman (UNT), criado em 1987; o Instituto de Investigações Jurídicas e Sociais Ambrosio Lucas Gioja da Faculdade de Direito da Universidade de Buenos Aires; o Centro de Investigaciones de Filosofia Jurídica e Filosofia Social da Faculdade de Direito da Universidade Nacional de Rosário, e o Centro de Investigaciones Jurídicas y Sociales ligado à Faculdade de Direito e Ciências Sociais da Universidade Nacional de Córdoba. Existe ainda o Centro de Estudios Legales y Sociales (CELS), organismo não governamental fundado em 1979. Há constitucionalistas vinculados também à Academia Nacional de Ciências Morales y Politicas, fundada em 1938, que conta com vários "Institutos", sendo um deles dedicado à "Política Constitucional".

A pulverização de tais centros pelo país mostra que a estruturação do espaço dos constitucionalistas começou a ganhar força na década de 1970 e se intensificou com a redemocratização da década de 1980. Quanto à Reforma de 1994, vemos que ela repercutiu fortemente sobre o plano doutrinário como estratégia das elites políticas de reforçar a intersecção entre academia e esfera política. Uma iniciativa que ilustra essa ação foi o Seminário Nacional de $1995,{ }^{23}$ que reuniu uma expressiva nominata de políticos e juristas e redundou na publicação do manual coletivo La Constitución Argentina de nuestro tempo, lançado em 1996. ${ }^{24}$ Coordenado por Jorge Sáenz e pelo político Roberto Dromi, o manual representa a aposta coletiva de políticos e constitucionalistas na estratégia de legitimação da reforma através da vinculação da trajetória argentina à europeia, com grande ênfase no sistema espanhol. Do manual participaram 12 juristas espanhóis, ao lado dos 19 argentinos. ${ }^{25}$

A multiposicionalidade dos autores é um indicativo importante, pois na obra há uma mescla de discursos de políticos (deputados, ministros, fundadores de partidos políticos) e de professores e práticos do direito (magistrados, advogados e promotores), evidenciando uma das tendências das conjunturas de mudança política: a mobilização conjunta de políticos e juristas em torno da legitimação do novo regime. No caso argentino, isso remete às condições em que foi firmado o compromisso da elite política com as novas regras do jogo. 0 "núcleo de coincidências básicas" que deveria ser respeitado na mudança do texto constitucional foi definido pelas duas lideranças partidárias do momento: Carlos Menem do Partido Justicialista e Raul Alfonsín da União Cívica Radical. Eles firmaram no Pacto de Olivos a base de sustentação da Reforma Constitucional de 1994, que, fruto de um acordo de líderes, demandaria amplo apoio parlamentar e adesão popular para ser aprovada e legitimada. 
Essa reforma promoveu, portanto, uma nova alavancagem da produção doutrinária, o que pode ser constatado em uma busca simples pela internet a partir do critério Reforma de la Constitución. 0 título pesquisado apresentou um total de 37 manuais de Direito Constitucional, sendo 7 anteriores e 27 posteriores à Reforma de 1994. ${ }^{26}$ Além disso, é relevante frisar a expressiva inserção política dos autores formando um conjunto de juristas-políticos e políticos-juristas: 13 agentes, em um total de 19, atuaram em partidos políticos, no Parlamento e/ou no Poder Executivo. Sete são egressos da Universidade de Buenos Aires e 6 da Universidade de Córdoba, indicando o predomínio desses dois centros de formação jurídica no espaço da doutrina. Uma significativa fração atuou ainda como juiz da Suprema Corte da Nação ou exerceu funções judiciais. Sete foram partícipes da Convenção Constituinte de 1994.

As décadas de 1990 e 2000 foram caracterizadas pelas mudanças políticas frequentes nos postos da Presidência da República Argentina, implicando a queda e a ascensão de orientações distintas de governo e a adoção de medidas conjunturais, como a dolarização da economia. Os sucessivos planos econômicos de urgência em face das crises políticas agudas e permeadas de mobilizações sociais foram acompanhados da ascensão dos juristas impulsionados pela Reforma Constitucional de 1994. Da queda de Fernando La Rúa, em 2001, ao advento do "ciclo Kirchner", iniciado em 2003, o cenário argentino apresenta um quadro favorável à intensificação das batalhas doutrinárias que repercutem os embates públicos. Nesse cenário, grupos de constitucionalistas têm-se mobilizado, tanto em textos jurídicos como em opiniões na mídia, aparecendo uma fração contestadora do "neoliberalismo" ou da redução do papel do Estado, reivindicando um compromisso com os direitos econômicos e sociais, como a "Escola Social" da doutrina sobre a Constituição. Situam-se nesse polo juristas como Héctor Sandler, Roberto Gargarella e Federico Gaston Thea. De outro lado, constatamos tomadas de posição acadêmicas e na imprensa que se identificaram com as críticas a diversas iniciativas políticas que marcaram o governo de Cristina Kirchner, como a Lei de Meios. Neste caso, destacam-se os constitucionalistas Alberto Sabsay e Gregório Badeni, este com uma coluna permanente no periódico La Nación.

\section{CONSIDERAÇÕES FINAIS}

E sta exploração do caso argentino permitiu constatar que o constitucionalismo tem sido percebido pelas elites políticas como ferramenta de poder simbólico onde o ensino da doutrina constitucional foi apropriado e redefinido por sucessivos regimes políticos. Desde a Reforma Constitucional de 1994 percebemos que o cenário de midiatização do debate político deu maior visibilidade à força simbólica do constitucionalismo, favorecendo a valorização da expertise dos 
constitucionalistas no debate público. Em grande medida legitimados por uma formação e atuação docente em Universidades Públicas Nacionais, sobretudo a Universidade de Buenos Aires, a fração dominante desses agentes ostenta um padrão de forte internacionalização, tanto através da pós-graduação no exterior quanto da integração em redes jurídicas internacionais.

Embora estreitamente vinculados ao jogo político e muitas vezes a polarizações radicais no espaço político, a expertise constitucional enquanto recurso para a formalização jurídica dos discursos políticos consolidou-se no debate argentino, realimentando a apropriação da política pelos constitucionalistas. Resta investigar se a penetração do debate constitucional no debate político contribui para a maior estabilidade e universalização dos sentidos de supremacia da Constituição, ou se a mobilização da expertise constitucionalista aparece reduzida a mais uma arma de combate no âmbito de batalhas políticas conjunturais.

\section{Notas}

1 Empregamos nesta análise a definição weberiana de legitimidade, de onde se extrai que: "Toda a ação, especialmente a social e, por sua vez, particularmente a relação social podem ser orientadas, pelo lado dos participantes, pela representação da existência de uma ordem legítima. A probabilidade de que isto ocorra de fato, chamamos 'vigência' da ordem em questão" (Weber, 2012: 19).

2 Para maior detalhamento sobre a relação entre os modelos jurídicos-políticos latino-americanos e a matriz europeia ver Perdomo \& Fix-Fierro (2003).

3 Artigo construído a partir do Projeto de Pesquisa "Legitimidade Política do Poder Judicial na América Latina: configurações institucionais e sócio-políticas do Judiciário e suas elites na Argentina, Brasil, Chile, Colômbia e Venezuela na década de 2000", financiado pelo CNPq.

4 Para mais detalhes ver Dezalay (1993), e para o caso dos juristas brasileiros ver Engelmann (2008).

5 Charle (1997) compara dois modelos de reprodução social: um primeiro ligado ao Ancien Régime e ancorado em estratégias de poder tradicionais, baseadas na formação e manutenção das grandes famílias de juristas, e outro que emerge com a ascensão da burguesia, com efeitos de diferenciação social.

6 A metodologia empregada, denominada sócio-histórica (Charle, 1989 e 1997; Buton e Mariot, 2009) permite situar o objeto de estudo (que é a implicação entre constitucionalismo e política) no âmbito da construção social da representação do especialista em interpretação da Constituição. Para captar a acumulação de capital doutrinário que contribui para a autonomização do espaço dos juristas é necessário adotar uma perspectiva temporal de longa duração, pois somente reinserido na história social nacional é que o fenômeno dos usos políticos do Direito pode ser apreendido em suas condicionantes múltiplas.

7 Ver Tanzi (2011). 0 texto, publicado no periódico Academia - Revista sobre la Ensenanza del Derecho, traz indicações sobre o percurso dos docentes em uma perspectiva temporal extensa, desde o século XIX.

80 emprego nativo da expressão "doutrina jurídica" ao invés de "teoria jurídica" não deve ser desprezado, pois indica a opção dos juristas pelo fechamento do campo, através de uma forma de discurso blindado contra as "intrusões" do questionamento e da refutação científica, próprias do caráter das "teorias". 
9 Os manuais jurídicos de Direito Constitucional são o formato privilegiado da prática de poder que é interpretar a Constituição, isto é, trata-se de um tipo específico de discurso que mobiliza a força simbólica do Direito. Por isso, esse discurso concentra e sintetiza em linguagem relativamente hermética os conhecimentos considerados mínimos, básicos ou fundamentais dessa expertise. Dirigidos ao público amplo, desde o futuro bacharel ao leigo interessado em conhecer o funcionamento da engrenagem jurídica (política), os manuais têm uma dimensão pedagógica que se associa, portanto, de modo ideal, à tarefa simbólica da elite política: educar o povo, educar o cidadão e educar a própria elite.

10 Conforme rol de Universidades na Argentina, disponível em: www.atillo.com. Acesso em 11/01//2016.

11 Disponível em: http://www.ambito-juridico.com.br/site/?n_link=guia_indice\&con_id=2\&pais_id=11\& tipo_i=6\&pagina=1_236__Acesso em 11/01/2016.

12 Dezalay e Garth (2015) analisam o caso da Índia e apontam de modo detalhado como os constitucionalistas indianos se relacionam com a elite econômica e política, projetando-se no cenário nacional, mobilizando seu capital familiar e a formação em Universidades centrais do país para atuar em grandes escritórios e chegar aos casos de repercussão na advocacia, perante os altos tribunais e a Corte Suprema.

130 advogado Juan Bautista Alberdi se encarregou de escrever o manual Bases e pontos de partida para a organização da República Argentina, livro que cumpriu a função de propor aos constituintes reunidos em Santa Fé "um projeto de Constituição e o fundamento teórico deste novo país que se preparava para empreender sua marcha ." (Luna, 1996: 67).

14 Para uma discussão sobre o período da Confederação Argentina e dos problemas e conflitos de unificação nacional em face da posição de Buenos Aires, ver Luna (1996).

150 país ainda não contava nem com docentes nacionais especializados nessa disciplina, nem com uma produção bibliográfica de Direito Constitucional nacional. A matéria estava situada na dimensão mais ampla do Direito Público e inicialmente foi ministrada pelo jurista colombiano Florentino González, em uma simbiose com o Direito Administrativo e mesmo com a Filosofia Política (Tanzi, 2011: 88). Durante as primeiras décadas do século XX, o investimento das elites no Direito Constitucional foi assistemático, porém devemos salientar que as reformas constitucionais de 1860, 1866 e 1898 provocaram tanto sucessivas reformas do ensino jurídico quanto grande rotatividade dos docentes na disciplina.

16 Esse debate pode ser considerado um marco relevante da mobilização da doutrina jurídica para usos políticos na transição entre os séculos XIX e XX. Para maior detalhamento do conteúdo das batalhas doutrinárias envolvendo os publicistas da região platina, ver Bouzas (2006).

170 Grupo Azcuénaga foi a instância cultural de natureza coletiva criada durante o Regime de 1955 para agregar os intelectuais de várias especializações em torno da legitimação do sistema político. Para mais informações sobre a composição e atuação desse grupo, ver Moressi ( 2010) e Vicente (2012).

18 Para uma discussão sobre o contexto de ocorrência do Golpe Militar de 1930 e os aspectos que caracterizaram o Regime Autoritário estabelecido na Argentina de 1930 a 1943, ver Luna (1996), sobretudo o capítulo X.

19 Para uma análise sobre as condições em que atuou a Comissão Assessora formada por constitucionalista, S ver Lorenzo (2000).

200 site do instituto apresenta seus propósitos: "0 Instituto Ibero-americano de Direito Constitucional (IIDC) foi fundado na cidade de Buenos Aires, Argentina, em 22 de março de 1974; eram tempos muito dif́ceis para a democracia na América Latina. Catedráticos argentinos e mexicanos, ao ter presente a realidade 
constitucional de nossos países, decidiram somar esforços". Disponível em: http://www.juridicas.unam.mx/ iidc/antecedentes.htm. Acesso em 24/03/2016.

21 A produção de manuais de Direito Político (Teoria do Estado e Direito Constitucional) e as análises da jurisprudência da Suprema Corte que compõem a produção doutrinária de German Bidart Campos seguem a orientação jusnaturalista teocêntrica, ou seja, a linha liberal católica, baseada na sustentação do papel da Justiça no sistema político da Argentina como garante dos direitos individuais. 0 manual La Corte Suprema: el tribunal de las garantías constitucionales em que explicita sua apropriação do sentido da supremacia da Constituição como garantia dos direitos individuais e da autonomia da Corte Suprema, foi publicado pela editora Ediar em Buenos Aires em 1982 e reeditado até 2010, o que aponta a significativa a extensão temporal da difusão de sua doutrina.

22 Conforme lista de associados publicada em 2015 e disponível no sítio da Associação: www.aadconst.org.ar.

23 Encontro organizado pela Faculdade de Direito da Universidade de Buenos Aires, pela Embaixada da Espanha e pela Fundação Centro de Estudios Políticos y Adminitrativos (CEPA).

24 Nomes relevantes da esfera política nacional integraram a obra, como Eliza Carrió, Fernando de la Rúa, Eduardo Menem, além de Robereto Dromi, ministro da área econômica responsável pelas privatizações ocorridas no governo Carlos Menem. 0 manual foi lançado em Buenos Aires pela Ediciones Ciudad Argentina e aparece na bibliografia da disciplina nas faculdades de Direito analisadas.

25 No entanto, esse "intercâmbio" de ideias ofereceu também suporte para a transformaç̧ão econômica europeia, pois Espanha e Portugal já atravessavam desde os anos 1980 uma série de crises e reformas. Para o caso específico da Espanha, ver a análise sobre a política e a economia dos anos 1990 em Souza (2007).

26 Disponível em: http://www.bibliotecas.ucasal.edu.ar Acesso em 20/01/2016.

\section{REFERÊNCIAS BIBLIOGRÁFICAS}

ALMEIDA, Frederico de. As elites da justiça: instituições, profissões e poder na política da justiça brasileira. Revista de Socioogia e Poítica [online], 2014, vol. 22, n. 52, p. 77-95. ISSN 1678-9873. (http://dx.doi. org/10.1590/1678-987314225206).

AVRITZER, Leonardo, BIGNOTO, Newton, FILGUEIRAS, Fernando, GUIMARÃES, Juarez e STARLING, Heloísa (orgs.). Dimensões políticas da Justiça. Rio de Janeiro: Civilização Brasileira, 2013.

BOURDIEU, Pierre. La force du droit. Eléments pour une sociologie du champ juridique. Actes de la Recherche em Sciences Sociales, vol. 64, septembre 1986, p. 3-19.

BOUZAS, Raquel García. Los debates de los juristas rioplatenses sobre la cuestión social a comienzos de siglo. Estudios de Filosofía Práctica y Historia de las Ideas. Revista Anual de la Unidad de Historiografía y Historia de las Ideas, INCIHUSA/Mendoza. Año 7/no 8, diciembre 2006, p. 115-126.

BUTON, François \& MARIOT, Nicolas (dir.). Pratiques et méthodes de la socio-histoire. Paris: Presses Universitaires de France, 2009.

CHEVALIER, Jacques. Les Interprètes du Droit. In: POIRMEUR, Yves et BERNARD, Alain (dirs). La Doctrine Juridique. Paris: Presses Universitaires de France, 1993, p. 259-280.

COMMAILLE, J.; DUMOULIN, L. et ROBERT, C. (dirs.). La juridicisation du politique. Paris: LGDJ, 2010. 
DALLA VIA, Alberto Ricardo. El Derecho Constitucional: entre La doctrina y el discurso. Buenos Aires: La Ley, 2007.

DEZALAY, Yves e GARTH, Bryant. A construção jurídica de uma política de notáveis: o jogo duplo da elite do judiciário indiano no mercado da virtude cívica. Revista Pós Ciências Sociais - REPOCS -Dossiê Profissões e Espaços da Política. São Luís do Maranhão, vol. 12, n.23, jan/jun 2015, p. 37-60.

DROMI, Roberto e SÁENZ, Jorge (coord.). La Constitucion Argentina de nuestro tiempo. Buenos Aires: Ediciones Ciudad Argentina, 1996.

ENGELMANN, Fabiano. Sociologia do campo jurídico: juristas e usos do direito. Porto Alegre: SAFE, 2006.

e PENNA, Luciana. Política na forma da lei: o espaço dos constitucionalistas no Brasil democrático. Lua Nova - Revista de Cultura e Política, São Paulo, n. 92, 2014, p. 177-206.

e BANDEIRA, Júlia V.V.M. Poder Judiciário e política na América Latina: Argentina, Brasil, Chile e Colômbia e Venezuela em perspectiva comparada. VIII Congresso Latinoamericano de Ciência Política da Associacion Latinoamericana de Ciência Política-ALACIP, 2015.

FRANÇOIS, Bastien. Naissance d'une Constitution. La Cinquieme République: 1958-1962. Paris: Presses de SciencesPo, 1996.

. Le droit saisi par la politique. In : LAGROYE, Jacques (dir.). La politisation. Paris: Belin, 2003, p. 373-385.

FREER, Jaime Baeza. Élites, Path Dependency y la falta de un Pacto Constitucional estable en Chile y Argentina: um análisis comparativo-histórico. Política - Revista de Ciência Política. Santiago de Chile, vol. 50, no 2, 2015, p. 63-86.

GANDINI, Nicolás. Roberto Dromi, el ideólogo de una maniobra que pone a De Vido em la mira judicial. Perfil, 21/07/2015. Disponivel em: http://www.perfil.com/politica/Roberto-Dromi-el-ideologo-de-una-maniobra-que-pone-a-De-Vido-en-la-mira-judicial-20150718-0012.html. Acesso em 18/10/2016.

GRILL, Igor Gastal e REIS, Eliana Tavares dos. A universidade como um viveiro de vocações políticas: carreira profissional, notabilização intelectual e afirmação política. Revista Pós Ciências Sociais - REPOCS - Dossiê Profissões e Espaços da Política. São Luís do Maranhão, vol. 12, n.23, jan/jun 2015.

HERRERO, Álvaro. La incidência de la Corte Suprema de Justicia en laformulación de políticas públicas: una exploración empírica del caso argentino. Política - Revista de Ciência Política do Instituto de Asuntos Públicos de La Universidad de Chile. Santiago de Chile, vol. 49, n. 1 (Derecho, Justicia y Política), 2011, p. 71-106.

LACROIX, Bernard et LAGROYE, Jacques (dir.). Le Président de La République. Usages et génèses d'une institution. Paris: Presses de la Fondation Nationele des Sciences Politiques, 1992.

LÓPEZ, Griselda Marina. La reforma constitucional argentina de 1994 y el arte de la negociación menemista (1992-1994). Revista de Ciencia Política (Revista no 1 América Latina Del Siglo XX "Repensando la década del noventa). Disponível em: http://www.revcienciapolitica.com.ar/num1 1art4.php. Acesso em 22/12/2015.

LORENZO, Celso Ramón. Manual de História Constitucional Argentina - vol 3. Rosário: Editorial Juris, 2000.

LUNA, Félix. Breve história dos argentinos. Trad. Andrea Cecilia Ramal. Rio de Janeiro: Instituto Cultural Brasil-Argentina/ Quartet Editora, 1996.

MORESSI, Sergio. El liberalismo conservador y la ideologia Del Proceso de Reorganización Nacional. Sociohistórica - Cuadernos del CISH - 27. Primer semestre 2010, p. 103-135. 
NEVES, Lúcia Maria Bastos Pereira das. Corcundas e constitucionais: a cultura política da Independência (1820-1822).Rio de Janeiro: Revan/FAPERJ, 2003.

PENNA, Luciana Rodrigues. Usos políticos da "doutrina jurídica": a invenção da "interpretação constitucional" no Brasil Império. Tese de Doutorado no Programa de Pós-Graduação em Ciência Política - Universidade Federal do Rio Grande do Sul. 2014.

PERDOMO, Rogélio. Justicias e injusticias en Venezuela: estudios de historia social del derecho. Caracas: Academia Nacional de la Historia, 2011.

y FIX-FIERRO, Hector (orgs.) Culturas juridicas latinas de Europa y América en tiempos de globalizacion. México: Unam, 2003. Disponível em http://biblio.juridicas.unam.mx/libros/libro.htm?l=1078.

PIVATTO, Priscila Masdalozzo. Mecanismos de alteração constitucional: um estudo comparado das estruturas constitucionais da Argentina (1853/1860), Suíça (1848/1874) e Brasil (1891). Direito, Estado e Sociedade, n. 30, jan/jun 2007, p. 102 a 124.

POIRMEUR, Yves. Thèemes et débats autour du constitutionnalisme. In : Droit et Politique. Paris: Presses Universitaires de France, 1993, p. 13-39.

et ROSENBERG, Dominique. La doctrine constitutionnelle et le constitutionnalisme français. In: LOCHAK, D. (dir.). Les Usages sociaux du droit. Paris: Presses Universitaires de France, 1989.

SACRISTE, Guillaume. La republique des constitutionnalistes. Professeurs de droit et légitimation de l'État en France (1870-1914). Paris: Presses de SciencesPo, 2011.

SANTAMARIA, Ángela; VECCHIOLI, Virgínia (orgs.). Derechos humanos en América Latina: mundialización y circulación internacional del conociemento experto jurídico. Bogotá: Ed Universidad del Rosario/Centro de Estúdios Políticos Internationales, (2008.

SOUZA, Angelita de Matos. As transformações recentes da economia espanhola e sua expansão internacional. Revista Espaço Acadêmico, 2007. Disponível em: http://www.espacoacademico.com.br. Acesso em 05/02/2016.

TANZI, Héctor José. La ensenanza del Derecho Constitucional en La Facultad de Derecho de Buenos Aires. Academia - Revista sobre La Ensenanza del Derecho, año 9, № 17. Buenos Aires, 2011, p. 85-112.

VECCHIOLI, Virginia. Las víctimas del terrorismo de Estado y la gestión del passado reciente em la Argentina. Papeles de CEIC, no 1, março/2013, p. 1-25.

Professionales del Derecho, activismo jurídico y creación de neuvos derechos. Hacia uma mirada compreensiva del derecho desde las ciências sociales. Revista Política, vol. 49, no 1, 2011, p. 5-18.

VICENTE, Martín Alejandro. Los intelectuales Liberal-Conservadores Argentinos y la última dictadura. El caso del Grupo Azcuénaga. Kairós - Revista de Temas Sociales. Universidad de San Luís, año 16, n. 29, mayo de 2012, p. 1-17.

WEBER, Max. Economia e sociedade. Vol. 1. Brasília: Editora Universidade de Brasília, 2012.

YANKELEVICH, Pablo. Diplomáticos, periodistas, espías y publicistas: la cruzada mexicana-bolchevique en América Latina. Revista HISTÓRIA, São Paulo, 28 (2): 2009, p. 495-514.

ZIMMERMANN, Eduardo. Abogados, científicos y estadistas. Debates sobre La enseñanza jurídica em la Argentina del primer Centenario. Revista Ciencia Hoy, vol. 20, n. 119, out-nov 2010, p. 36-42. 